\title{
Lidar validation measurements at the NOAA Mauna Loa Observatory NDACC station
}

\author{
Thomas J. McGee*a, Laurence W. Twigg ${ }^{b}$, John T. Sullivana, Thierry Leblancc, John Barnes ${ }^{d}$, \\ Grant K. Sumnicht ${ }^{\mathrm{b}}$, Stuart McDermid ${ }^{\mathrm{c}}$. \\ aNASA Goddard Space Flight Center, Atmospheric Chemistry and Dynamics Div., 8800

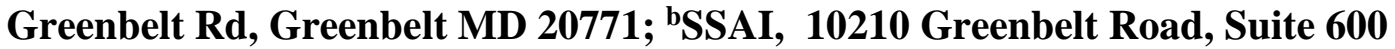 \\ Lanham, Maryland 20706: 'JPL Table Mountain Facility, 24490 Table Mountain Rd., \\ Wrightwood, CA, 92397; dNOAA ESRL Global Monitoring Division 325 Broadway R/GMD \\ Boulder CO 80305-3328
}

\begin{abstract}
NASA's Goddard Space Flight Center (GSFC) transported two lidar instruments to the NOAA facility at the Mauna Loa Observatory (MLO) on the Big Island of Hawaii, to participate in an official, extended validation campaign. This site is situated 11,141 ft. above sea level on the side of the mountain. The observatory has been making atmospheric measurements regularly since the 1950's, and has hosted the GSFC Stratospheric Ozone (STROZ) Lidar and the GSFC Aerosol and Temperature (AT) Lidar on several occasions, most recently between November, 2012 and November, 2015. The purpose of this extended deployment was to participate in Network for the Detection of Atmospheric Composition Change (NDACC) Validation campaigns with the JPL Stratospheric Ozone Lidar and the NOAA Temperature, Aerosol and Water Vapor instruments as part of the routine NDACC Validation Protocol.
\end{abstract}

Keywords: Lidar, ozone profiles, water vapor profiles, temperature profiles, NDACC validation

\section{INTRODUCTION}

The Atmospheric Chemistry and Dynamics Division of NASA's Goddard Space Flight Center has developed a number of ground and aircraft instruments for the measurement of atmospheric gases and parameters. Three of these instruments are affiliated with the international Network for the Detection of Atmospheric Composition Change (NDACC), with a Tropospheric Ozone (TropOz) lidar, an Aerosol and Temperature (AT) lidar and a Stratospheric Ozone (STROZ) lidar. The AT and STROZ lidars measure profiles from the troposphere to the mesosphere, and were the instruments deployed to the NOAA Mauna Loa Observatory. The two stratospheric lidar instruments were developed to be mobile validationstandard instruments for other similar instruments permanently installed at NDACC stations around the world. NDACC Validation Protocols call for periodic campaigns to demonstrate that the instruments are still functioning as expected. This commitment to validation of widely separated instruments, by a high quality research grade instruments, provides credibility for the NDACC data set as a whole. Such a validation program requires an instrument of similar, or higher, quality to the instruments being validated. One of the benefits of this validation program, however, is the identification and resolution of often subtle problem areas, or the lack of such problems, in instrumentation and algorithms at NDACC lidar sites; thereby increasing the credibility of the data sets generated by those instruments. Distinguishing between instrumental drift and geophysical changes is easier and far more credible when periodic calibrations take place. Because data gathered by sites around the world are often used to inform policy decisions, it is imperative that the data be proven to be credible. The work reported on in this paper is just such a validation campaign for NDACC instruments permanently housed and operated at the Mauna Loa Observatory - the validation of the NOAA Aerosol and Water Vapor Lidar and the JPL Stratospheric Ozone and Temperature Lidar using the Goddard Stratospheric Ozone Lidar, and the Goddard Aerosol and Temperature Lidar. The campaign was the NOAA, Goddard, IPL Intercomparison Experiment - designated NOGJIE in the text below. The campaign occurred in seven different time periods between November, 2012 and November, 2015. The STROZ Lidar participated until it was shipped to the Maido Observatory on Reunion Island in January, 2014. 


\subsection{The Stratospheric Ozone (STROZ) Lidar}

The first of these instruments to be developed, the STROZ lidar, detecting only elastically scattered signals from the transmitted 308 and $355 \mathrm{~nm}$ laser light ${ }^{1}$, has been active in the NDACC community since 1988. This instrument collects return signals using a 0.76 meter Dall-Kirkham telescope. After the eruption of Mt Pinatubo in 1991 injected millions of tons of $\mathrm{SO}_{2}$ into the stratosphere, the subsequent enhancement in stratospheric sulfate aerosols made the measurement of stratospheric ozone and temperature using purely elastic signals in those regions impossible. As a result, additional channels to detect radiation scattered as a result of Raman scattering of the transmitted wavelengths from atmospheric $\mathrm{N}_{2}$ were added to the instrument ${ }^{2}$. Removing any elastically scattered radiation in these Raman signals greatly improved the quality of the ozone and temperature retrievals ${ }^{3}$. More recently a $408 \mathrm{~nm}$ channel, and a small, 4 -inch telescope has been added to capture near field signals from elastically scattered $355 \mathrm{~nm}$ and Raman signals at 408 (water vapor) and 387 $\left(\mathrm{N}_{2}\right.$ Raman) $\mathrm{nm}$. This allows for water vapor and aerosol measurements down to approximately $2 \mathrm{~km}$ above the lidar instrument. The various detected signals, and the data products retrieved from each are shown schematically in Figure 1 below.

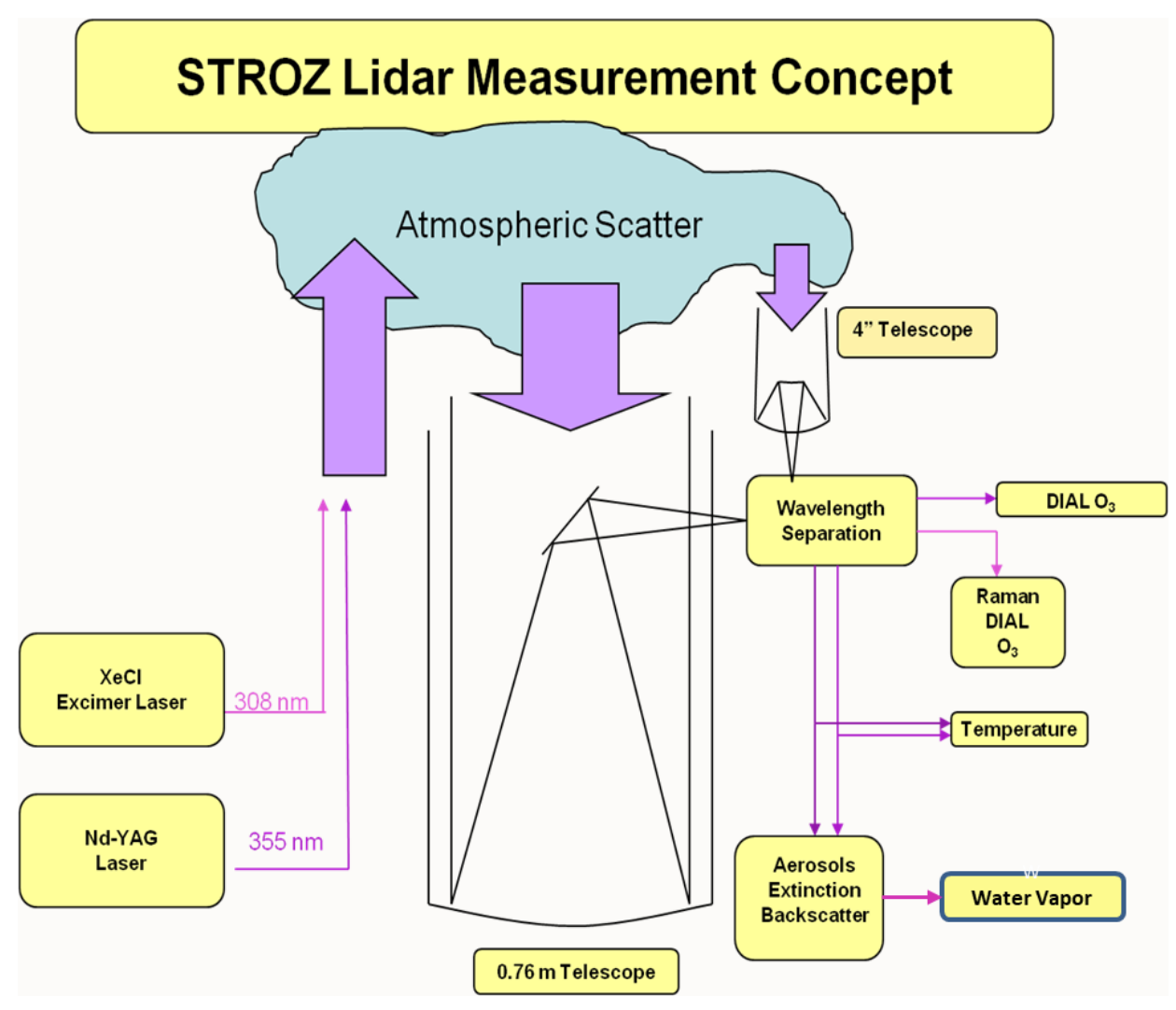

Figure 1. Schematic diagram of the GSFC STROZ lidar instrument as currently configured, showing the two telescopes and the data products retrieved.

\subsection{The Aerosol and Temperature (AT) Lidar}

The AT lidar began construction in 1991 to be a separate and more capable instrument for the measurement of stratospheric temperature and aerosols, transmitting 1064, 532.and $355 \mathrm{~nm}$ radiation from a Nd-YAG laser. The receiver was based on a 36.0 inch Newtonian telescope. In 1995 the detector section was significantly modified:

1) The Nd-YAG laser was injection-locked to narrow the linewidth of the laser output.

2) Additional wavelengths were added to the detection system (see table 1 below) 
3) GKSS collaborated with GSFC and loaned a tested and well documents rotational Raman polychromator for measurement of tropospheric temperature in the presence of aerosols and clouds ${ }^{4}$. The polychromator collects signals that are elastically and inelastically scattered from the line-narrowed output of the YAG laser $532 \mathrm{~nm}$

4) A 4" Cassegrain telescope was added to the instrument to extend the sensitivity to the near field

5) Depolarization channels were added to identify ice in clouds.

In total, the receiver includes 17 channels and Table 1 identifies the wavelengths detected and data products for which they are used. The AT Lidar has participated in numerous campaign for aerosols, temperature and water vapor.

Table 1. Wavelengths detected by the GSFC AT Lidar

\begin{tabular}{|c|c|c|}
\hline Wavelength (nm) & Telescopes used & Data Products \\
\hline 1064 & $36 ”$ & Aerosol Backscatter \\
\hline 607 & $36 ”$ & Raman Backscatter $\left(\mathrm{N}_{2}\right)$, Aer \\
\hline 532 & $36 ”$ & Aerosol Backscatter \\
\hline 530.85 & 36” & Temp Rotational Raman (Low T) \\
\hline 529.35 & $36 ”$ & Temp Rotational Raman (High T) \\
\hline 532 (perp) & $36 ”$ & Elastic Backscatter (Aer pol) \\
\hline 532 (para) & $36 ”$ & Elastic Backscatter (Aer depol) \\
\hline 408 & $36 ” .4 ”$ & Raman Backscatter $\left(\mathrm{H}_{2} \mathrm{O}\right.$ water vapor $)$ \\
\hline 387 & $36 ” .4 ”$ & Raman Backscatter $\left(\mathrm{N}_{2}\right)$ Aer., WV \\
\hline 355 & $36 ” .4 ”$ & Aerosol Backscatter \\
\hline
\end{tabular}

\section{AT Lidar Measurement Concept}

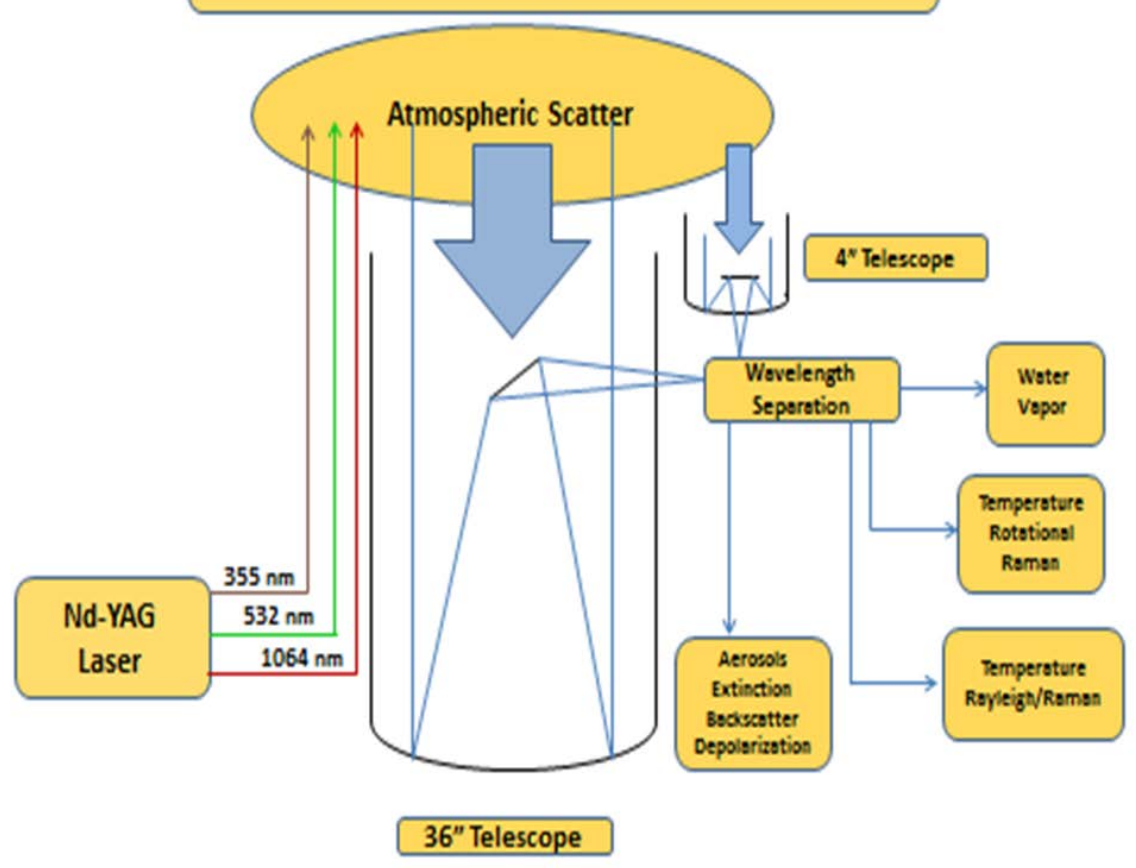

Figure 2. Schematic of the AT lidar showing the near field and the far field telescopes and the data products retrieved. 
The Mauna Loa campaigns feature instruments from NOAA, NASA, and JPL. These deployments were official NDACC validation campaigns evaluating the NOAA lidar for $\mathrm{H}_{2} \mathrm{O}$ profile measurements, and the JPL Stratospheric Ozone Lidar for $\mathrm{O}_{3}$, and Temperature profiles. Below we discuss the measurements and the data comparisons.

\section{MEASUREMENTS AND COMPARISONS}

The two GSFC lidar instruments were transported to the remote MLO station in August of 2012 and the first deployment of personnel to set up and begin the measurements took place in November of that year. At that time the two GSFC lidars, the JPL lidar and the NOAA lidar were all synchronized to a $200 \mathrm{~Hz}$ pulse from the JPL Lidar to a digital delay generator (DDG) which divided the $200 \mathrm{~Hz}$ signal to match the required rep rates for each of the other two lidar; the GSFC Ozone system utilized a $200 \mathrm{HZ}$ pulse for its' XeCl excimer laser (emitting at $308 \mathrm{~nm}$ ) and a $50 \mathrm{~Hz}$ pulse for a Nd-YAG laser (at $355 \mathrm{~nm}$ ); the GSFC AT Lidar required a $50 \mathrm{~Hz}$ signal for a Nd-YAG laser (1064, 532.25, $355 \mathrm{~nm}$ ): and the NOAA Lidar required a $25 \mathrm{~Hz}$ pulse for a Nd-YAG laser (1064, 532, $355 \mathrm{~nm})$. The DDG also provided appropriate delays for each lidar system so that no two instruments were transmitting at the same time. This avoided the cross-talk between lidars that occurs with instruments sited as closely as these were. Tables 1 and 2 below show the numbers of coincident nights of data were obtained for each of the two Goddard Lidars.

Table 1. AT Mobile Lidar Observational Data Summary NOGJIE Campaign

\begin{tabular}{|c|c|c|c|c|c|}
\hline $\begin{array}{c}\text { Deployment } \\
\text { ID }\end{array}$ & Dates & Total Nights & \multicolumn{2}{|c|}{ Coincident Nights } \\
\hline & & & STROZ (H2 O, T) & JPL (T) & NOAA (H2O) \\
\hline A & Nov. 11-Nov. 28, 2012 & 3 & 1 & ---- & 1 \\
\hline B & Feb. 02-Feb. 20, 2013 & 11 & 10 & 6 & 8 \\
\hline C & Apr. 30-May 16, 2013 & 13 & 5 & 8 & 8 \\
\hline D & Jul. 26 - Aug. 17, 2013 & 14 & 12 & 4 & 3 \\
\hline E & Jan. 15 - Jan. 25, 2014 & 5 & 2 & ---- & 12 \\
\hline F & Jan. 07 - Jan. 29, 2015 & 15 & -- & ---- & 2 \\
\hline G & Nov. 6 - Nov. 26, 2015 & 11 & ---- & & 8 \\
\hline
\end{tabular}

Table 2. STROZ Mobile Lidar Observational Data Summary NOGJIE Campaign

\begin{tabular}{|c|c|c|c|c|c|}
\hline $\begin{array}{c}\text { Deployment } \\
\text { ID }\end{array}$ & Dates & Total Nights & \multicolumn{3}{|c|}{ NOAA Coincident Nights } \\
\hline & & & AT (H2O, T) & JPL (O) O $_{3}$ ) & NOAA (H2O) \\
\hline A & Nov. 03 - Nov. 25, 2012 & 12 & 1 & 6 & 2 \\
\hline B & Feb. 02 - Feb. 20, 2013 & 12 & 10 & 6 & 5 \\
\hline C & Apr. 30 - May 24, 2013 & 8 & 5 & 3 & 8 \\
\hline D & Jul. 27 - Aug. 17, 2013. & 12 & 12 & 5 & 11 \\
\hline E & Jan. 15 - Jan. 16, 2014 & 2 & 2 & 2 & --- \\
\hline
\end{tabular}




\subsection{Ozone Measurements}

These measurements involved both the JPL Stratospheric Ozone Lidar ${ }^{5}$ and the GSFC STROZ lidar. During the time that the STROZ was deployed to MLO for this series of validations, there were 21 nights of coincident ozone measurements, between these instruments. During any of these NDACC validation periods the first thing that is checked is the altitude registration of each instrument. The STROZ system was directly measured, and the registration between the two instruments was measured against the altitude of a stable, thin cirrus cloud. During the first measurement period (A), the JPL system was found to be off by 300 meters, which was traced to an accidental change of $2 \mu$-sec in the firing sequence of the excimer laser. This was corrected and the previously acquired data were also corrected to reflect the proper altitude registration. Figure 3 below, shows the results of the 21 measurements in two panels. The left panel shows the average ozone concentration retrieved by each instrument, and the right panel shows a difference plot in \% along with the 1- $\sigma$ uncertainties. There are two areas of departure between the two lidar retrievals, at high altitudes and at low altitudes. In the ozone case shown here, the uncertainties are large enough to indicate that the measurements are consistent with one another. At high altitudes, the measurements are compromised by low concentrations of ozone and uncertainties in the background subtraction during the retrievals, while at low altitudes, the differences are a result of the uncertainty in determining the saturation correction. In these cases the estimated uncertainties encompass the differences. The comparison shows excellent agreement between the two instruments with less than $10 \%$ difference from 17 to $45 \mathrm{~km}$, and less than 5\% between 20 and $42 \mathrm{~km}$. Above $45 \mathrm{~km}$ background subtraction errors and diminishing ozone are responsible for the increasing differences.

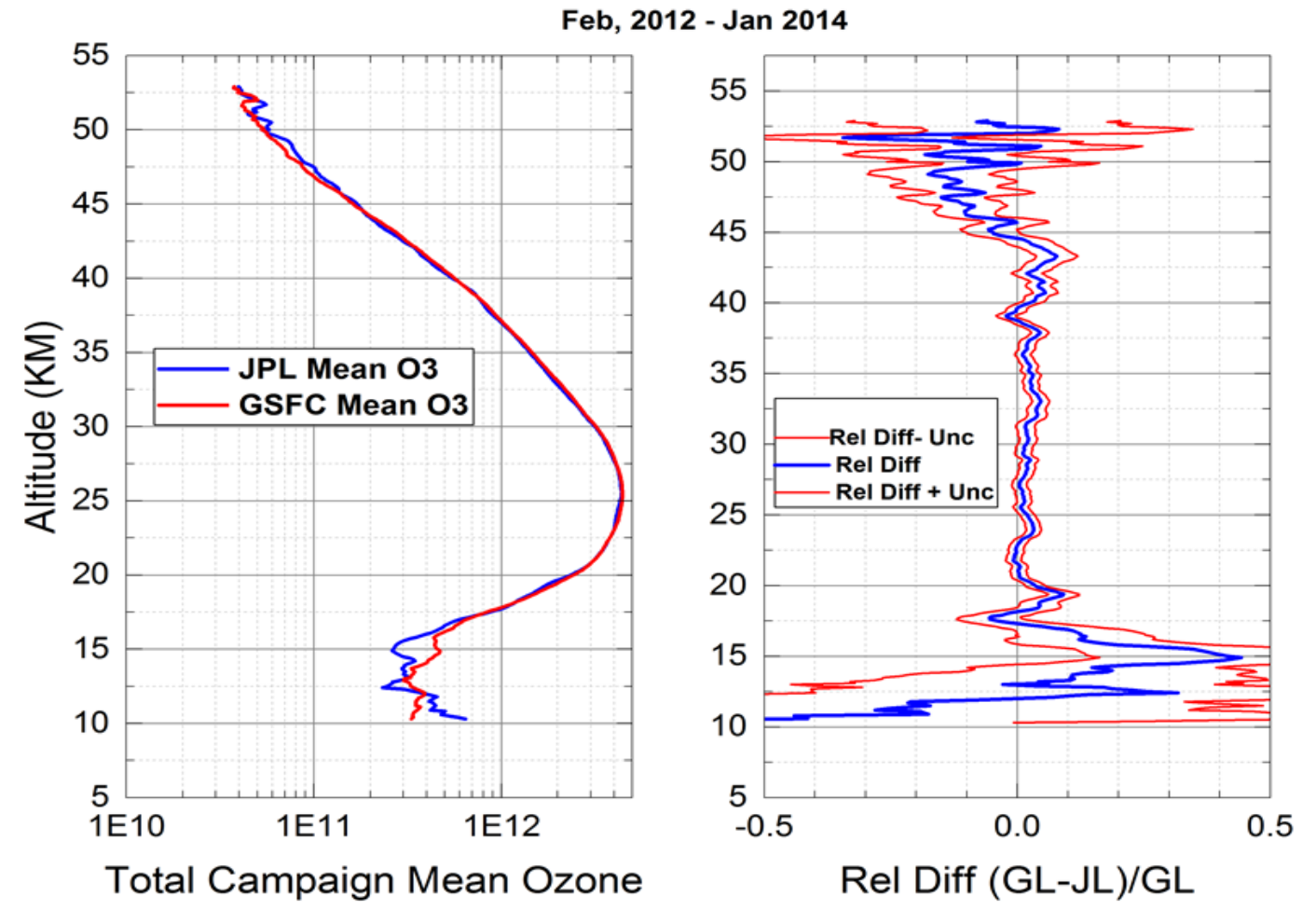

Figure 3. Results of 22 coincident ozone measurement at Mauna Loa Observatory between November, 2012 and January, 2014. GL- Goddard Lidar; JL- JPL Lidar. Ozone concentration is number density/cm

\subsection{Elastic/Vibrational Raman Temperature Measurements}

In the ozone section, only the JPL lidar and the STROZ lidar were capable of that measurement. In the case of the elastic/vibrational Raman temperature retrieval the JPL lidar and both GSFC lidars retrieve temperature. Again this is well documented in the literature ${ }^{6}$, and has been used within NDACC since 1993. During the MLO deployments there 
were 23 total coincident measurements between the GSFC AT Lidar and the JPL Lidar, and 22 coincident measurements between the GSFC STROZ Lidar and the JPL Stratospheric Lidar. The results of these measurement are shown in Figures 4 (a) and (b) below. Overall, there is agreement to within about $1 \mathrm{~K}$, however, there are two regions of difference. At high altitudes, differences are sometimes greater. The temperature profile is retrieved from a density profile, initialized to a high altitude model temperature. This was not always the same altitude for JPL as for GSFC and different models were used. At low altitudes, there are saturation corrections that are estimated differently by the two groups leading to the $2 \mathrm{~K}$ differences observed. In general the $1-\sigma$ uncertainties overlap the zero line, except below $15 \mathrm{~km}$

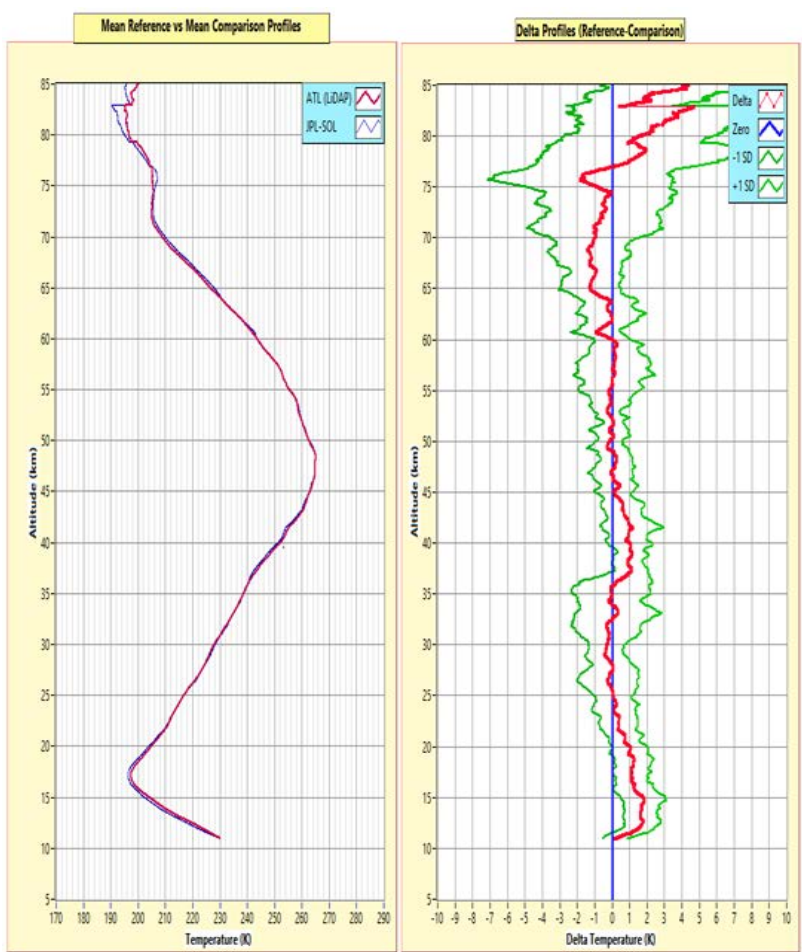

(a)

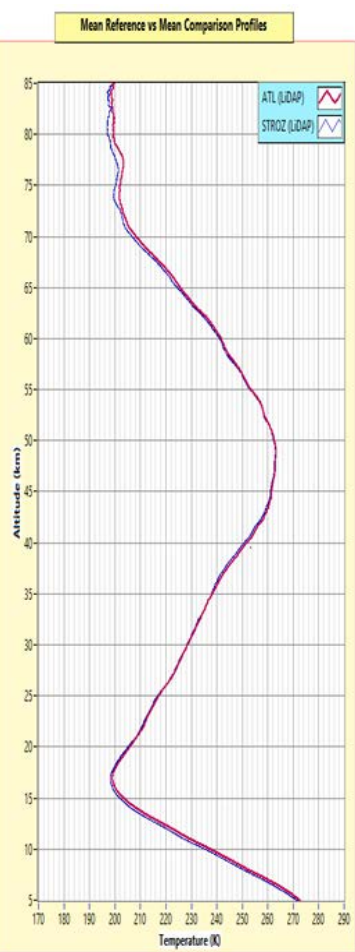

estute 1

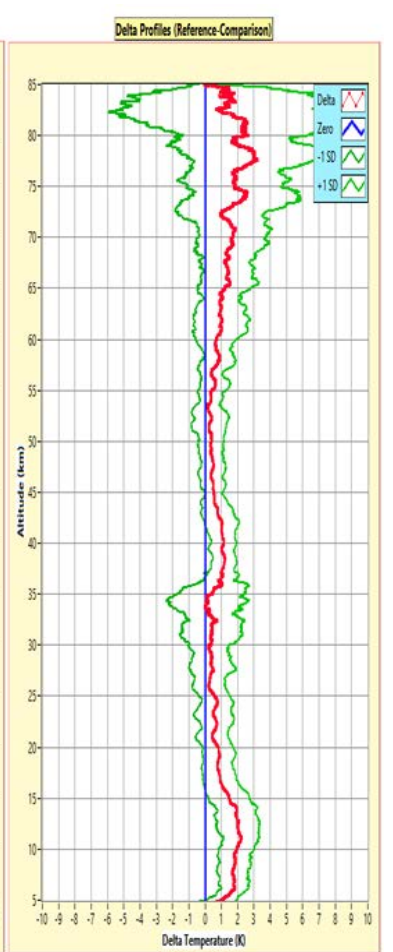

(b)

Figure 4. The retrieved temperature comparison between the GSFC AT lidar and the JPL Stratospheric Ozone lidar (a) and (b) the comparison between the JPL Lidar and the STROZ Lidar. There are 23 nights of measurements in (a) and 22 measurements in (b). Between 17 and $65 \mathrm{~km}$ there is generally less that one degree of difference between the instruments.

\subsection{Rotational Raman Temperature Measurements}

The usefulness of using the Rotational Raman method of temperature retrieval has been thoroughly reviewed ${ }^{7,8,9,10}$ and references therein. As mentioned in the Introduction section above, the GSFC AT Mobile Lidar trailer was equipped with the GKSS filter polychromator ${ }^{4}$, allowing the acquisition of data in the central 532.25 line as well as in two bands within the anti-Stokes branch of the spectral distribution of the 532nm lidar return. The ratio of these pure rotational Raman spectrum (PRRS) bands can be used to retrieve temperature via calibration using an independent source of temperature. This calibration source data can be temperature profiles from standard MET sondes, special science sondes, and/or data from another lidar or the AT lidar itself. The functional form used for deriving the nightly calibration coefficients is determined by the system, mainly by the exact characteristics of the filters used to detect the Raman bands. While a $4^{\text {th }}$ order fit is common, for the AT/GKSS system a linear fit is more than sufficient. The calibration curve for a single night using temperature data from the nearby Hilo MET sonde is shown below in Figure 5, using a simple fit of the form

$$
\mathrm{T}=\mathrm{Ax}+\mathrm{B}
$$

where $\mathrm{T}$ is the temperature and $\mathrm{x}$ is the ratio of the signal from the 2 Rotational Raman data channels (RRR).. For our calibration process we use the RRR obtained between $\sim 5$ to $15 \mathrm{kms}$ in order to use the best signal to noise data that also spans the full temperature range of interest ( ground to the tropopause). 

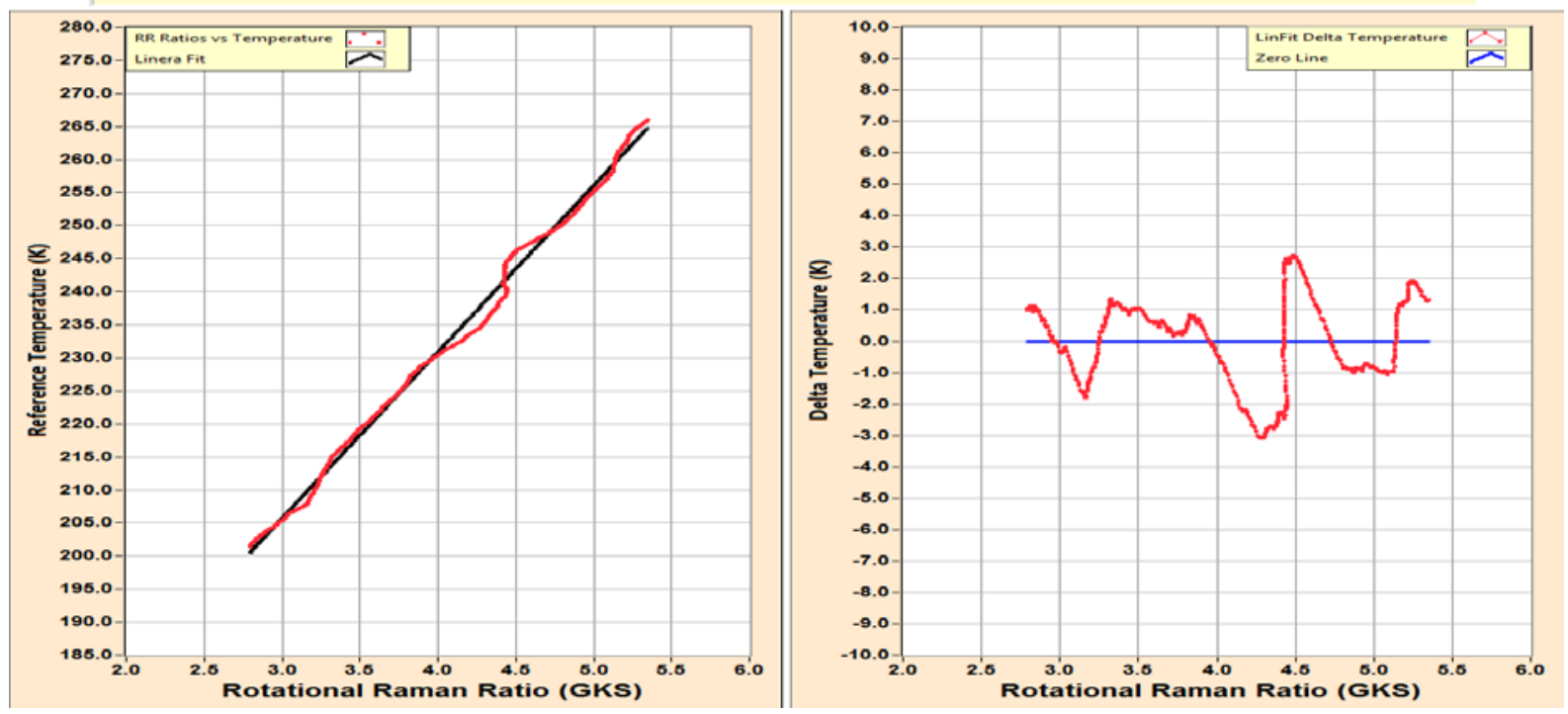

Figure 5. Derivation of the Rotational Raman calibration coefficients from a linear fit, and using the HILO MET sonde temperature profile for 11/24/2012. The left panel shows the raw data (red) vs. derived linear fit (black line), while the right panel shows the associated fitting residuals (i.e. delta temperature vs RRR)

To test the stability of the Rotational Raman calibration coefficients, a set of Rotational Raman calibration coefficients for the first 3 deployments were derived using the same linear model as shown above for 11/24/2012. Note that we show two possible calibrations of our Rotational Raman ratio (RRR) in figures 6 and 7 below. In figure 6, we use the temperature profile from the Hilo MET sonde, and for a comparison, figure 7 shows a calibration using the LiRAM (the Rayleigh-vibrational Raman temperature profiles). Figure 7 is of interest as the LiRAM temperature profile is derived from totally different data channels, and with the data acquired simultaneously with the Rotational Raman temperature channels. For this second case we did not use data that was obviously contaminated by clouds.

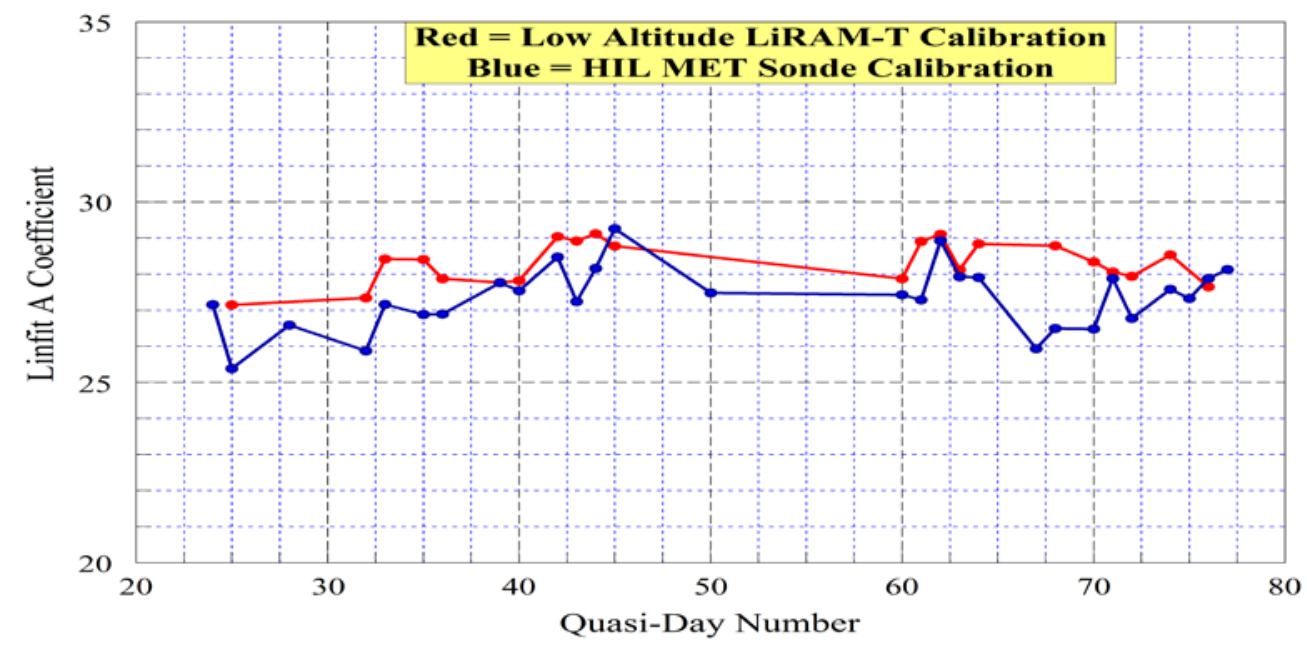

Figure 6. Rotational Raman calibration A-coefficient History during NOGJIE parts A-C. LinFit refers to the linear function fit used as described above. The $\mathrm{X}$-axis is a simple day number scheme to enable conveniently plotting the data from 3 deployments on one graph. 


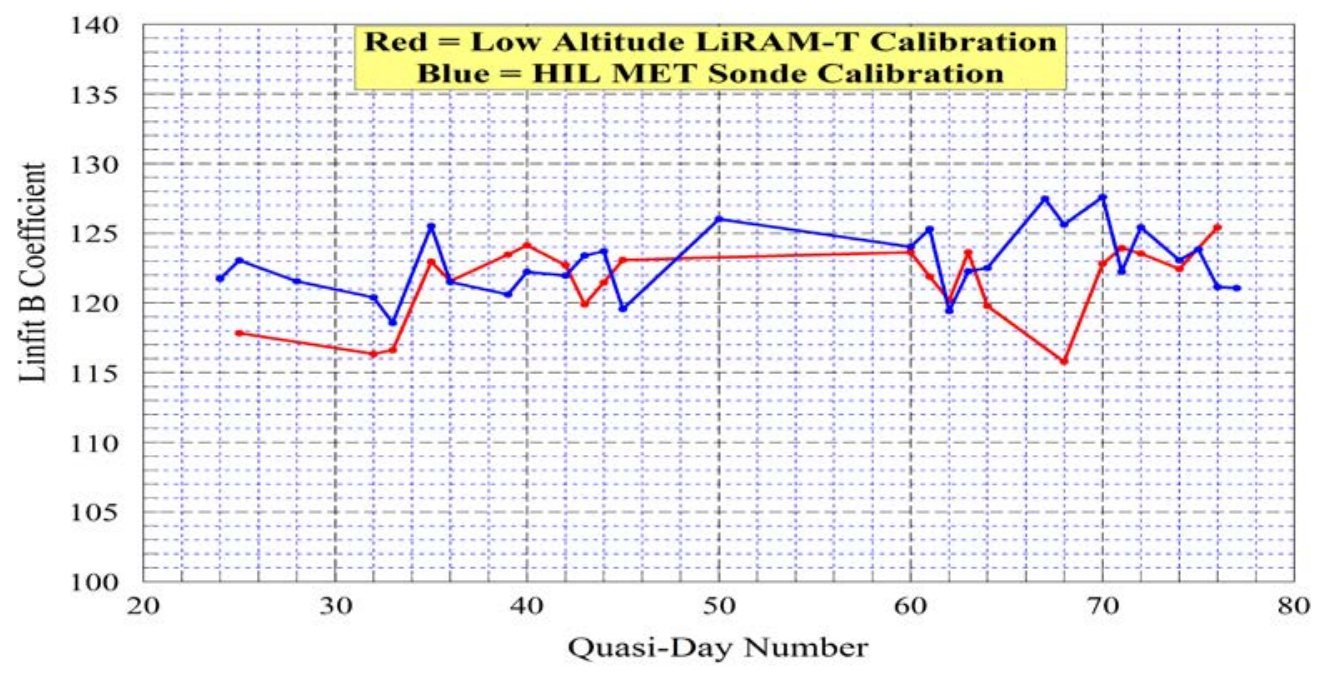

Figure 7. Rotational Raman calibration B-coefficient history during NOGJIE parts A-C. LinFit refers to the linear function fit used as described above. The $\mathrm{X}$-axis is a simple day number scheme to enable conveniently plotting the data from multiple deployments on one graph.

One can look at the deviations from a mean fit to the A and B-coefficients we derived above in order to look for trends. These deviations from the mean are shown below in Figures 8 and 9.

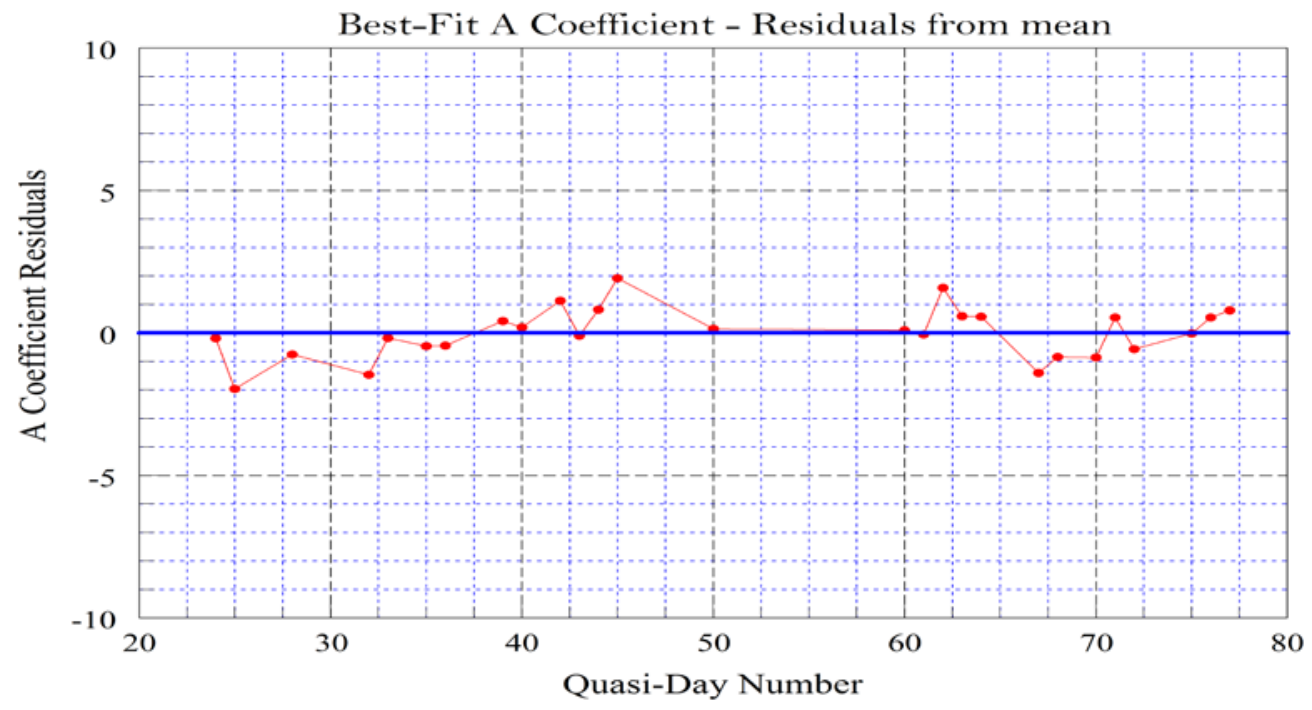

Figure 8. Deviations from the mean of the A-coefficient. The X-axis is a simple day number scheme to enable conveniently plotting the data from 3 deployments on one graph. 


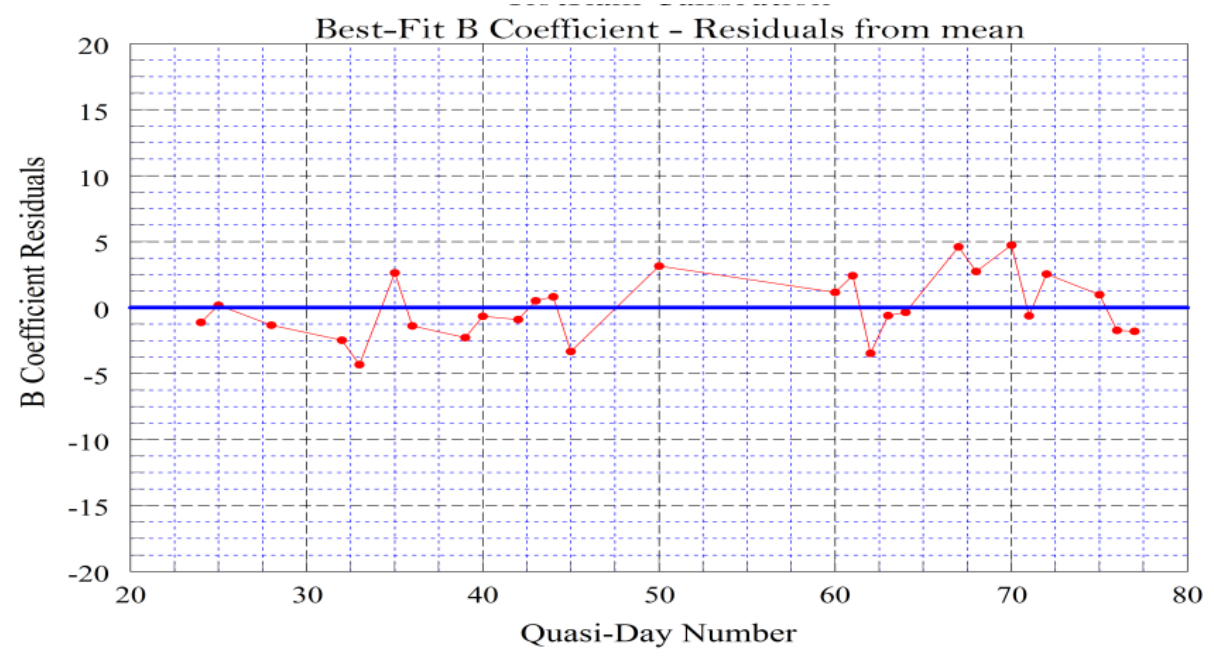

Figure 9. Deviations from the mean of the B-Coefficient. The X-axis is a simple day number scheme to enable conveniently plotting the data from 3 deployments on one graph.

For the Hilo Sonde calibration analysis yield a mean value of A as 27.4 and a standard deviation (SD) of 0.89 , thus an approximate error of 3.3\%. Similarly for the B coefficient the residual curves gives a mean of 122.9 and an SD of 2.4, or an error of 2\%. Thus the scatter over these three deployments (Feb-August 2013) is less than 5\% during this time period. While not shown, the LiRAM calibration analysis yields a similar result. In that we get a mean value of A is 28.4, with an SD of 0.71, thus an approximate error of 2.5\%, and for the B-coefficient a mean of 121.4, SD of 2.8, or an error of $2.3 \%$.

Finally, figures 10 and 11 show the A and B coefficients for the entire campaign, with a view showing that, after work on the fiber that couples the main detector package with the GKSS polychromator, the changes are reflected in the linear fit calibration coefficients. Figure 10 displays the A-coefficient history during the campaign, while Figure 11 displays the B-coefficient history. The large jump in the B coefficient seen at the far left side of Figure 10 is a result of realigning the fiber leading to the polychromator

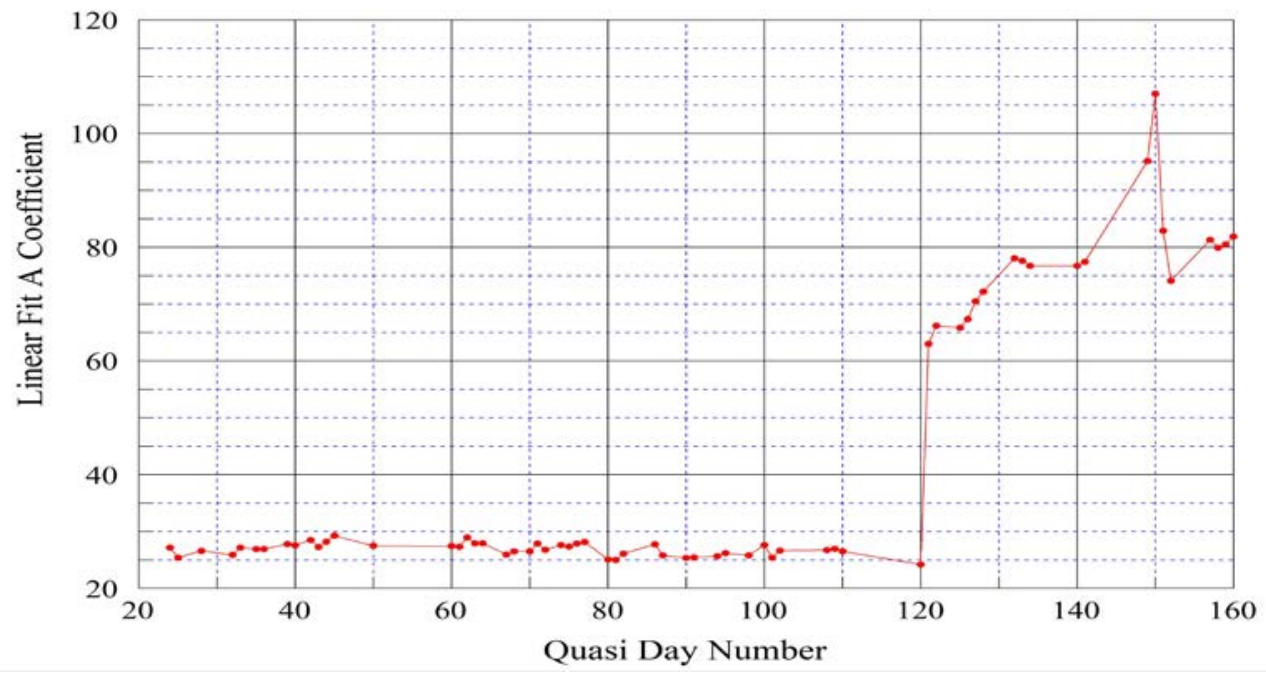

Figure 10. Full history of the A coefficient during the NOGJIE campaign. The X-axis is a simple day number scheme to enable conveniently plotting the data from all deployments on one graph. 


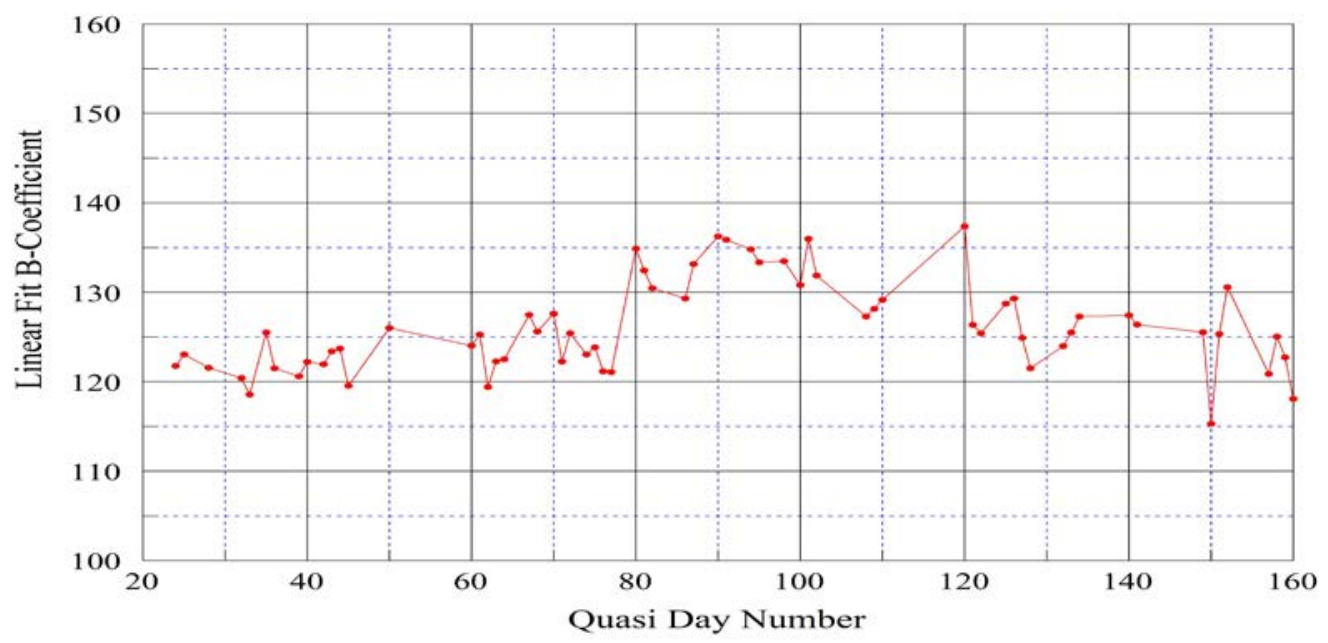

Figure 11. Full history of the B coefficient during the NOGJIE campaign. The X-axis is a simple day number scheme to enable conveniently plotting the data from all deployments on one graph.

Using the coefficients determined from the linear fit shown above (11/24/2012) we can generate Figure 12 shown below. It shows the Rayleigh, Rayleigh-Raman, and Rotational Raman temperature retrievals as well as several other reference temperature profiles (NMC, Hilo MET sonde, CIRA-86). Note that despite the very heavy cloud layer at $~ 8.5 \mathrm{kms}$, and its effect on the Rayleigh and Vibrational-Raman temperature retrievals, the Rotational Raman curve matches the MET sonde and NMC model extremely well. Note also that the use of the Raman $387 \mathrm{~nm}$ data for the temperature retrieval below $\sim 32 \mathrm{kms}$ results in a much better fit to the MET sonde around $27 \mathrm{kms}$, implying a likely aerosol layers in this around altitude range. There is a significant improvement in the temperature retrieval at the coldest point in the profile. The differences between temperatures retrieved from both elastic scattering and vibrational Raman scattering are significantly colder at the coldest point in the profile than the Rotational Raman, sonde, and NMC temperatures. In the cloud region, the elastic and vibrational-Raman temperatures are wildly colder than reality, while the rotational Raman temperature remains unperturbed by the presence of the cloud.

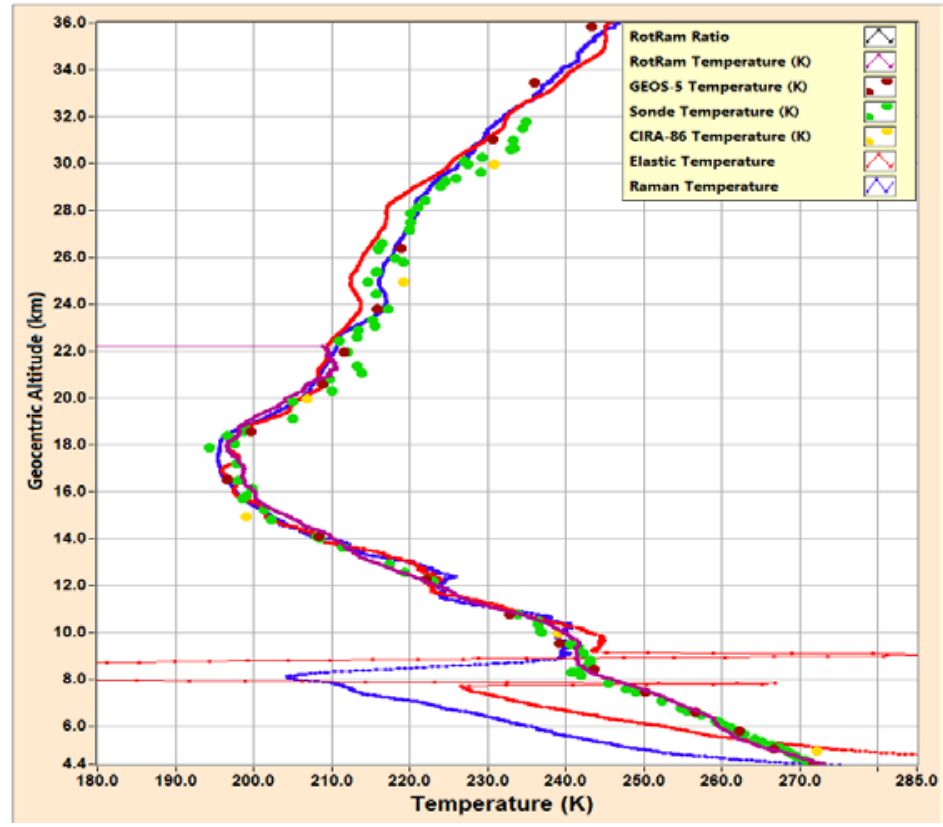

Figure 12. Comparison of the elastic (red), vibrational Raman (blue), rotational Raman (purple), GEOS-5 (brown), and Hilo MET sonde (green) for 11/14/2012. 
As a final illustrative example, we use our mean calibration coefficients from 61 available Hilo-MET sondes to generate Rotational Raman temperature profiles for the AT data acquired during NOGJIE deployments B-D, and compare those profiles to the corresponding GEOS- 5 temperature profiles. As the GEOS- 5 model generates profiles every 6 hours we obtain a very close match in time by using the 6 UT GEOS-5 temperature profiles. The results are shown in Figure 13 below. The lower part of the profile is limited to $5 \mathrm{~km}$ ASL due to difficulties in forming the saturation correction at high signal levels. The deviation from the GEOS-5 product is less than $1 \mathrm{~K}$ from just above $5 \mathrm{~km}$ to $22 \mathrm{~km}$.

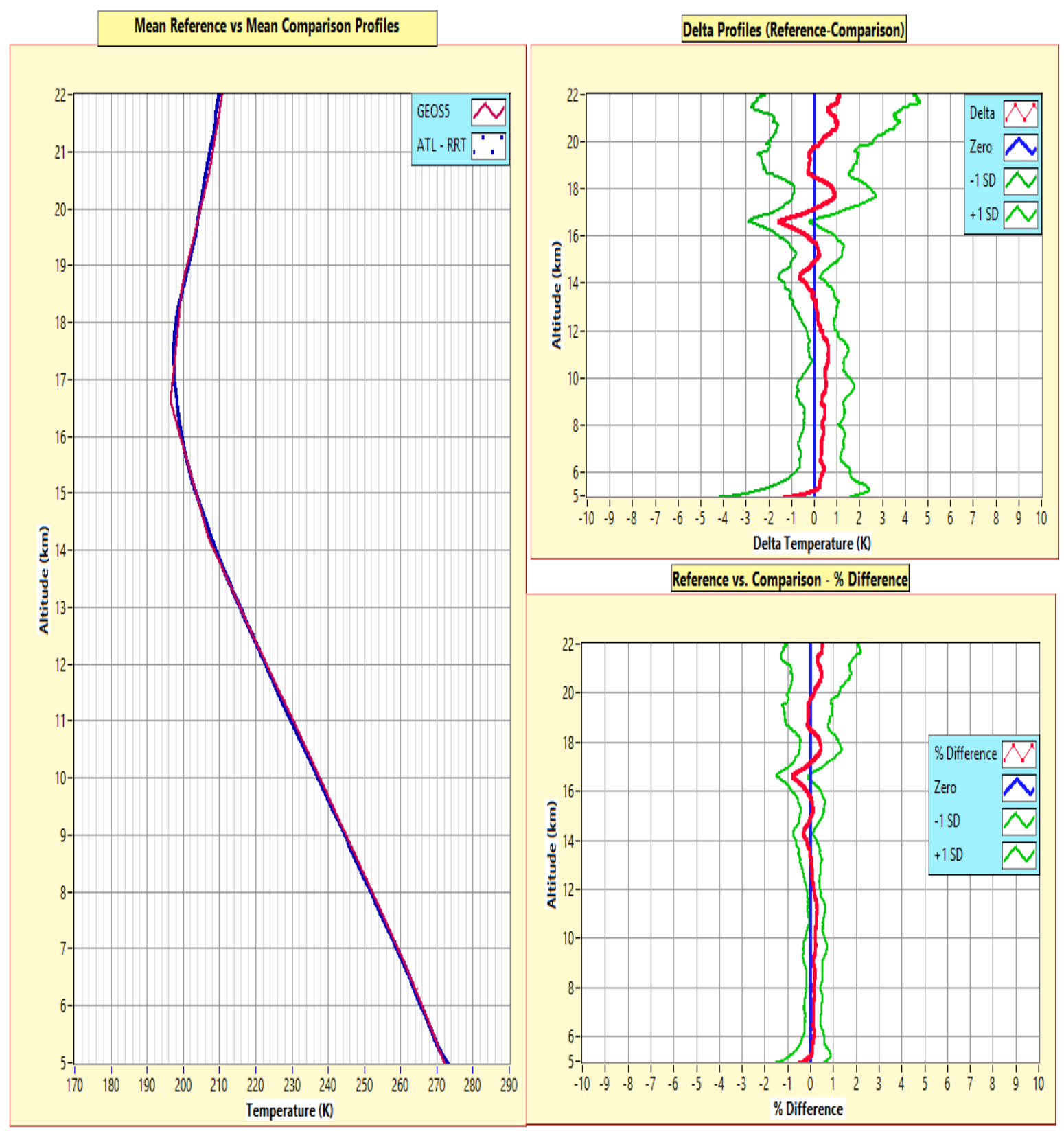

Figure 13. Summed AT Rotational Raman - GEOS-5 Temperature profile comparison for the NOGJE (B-D) deployments (41 profile pairs). The left plot shows the comparison between the mean AT (red) and GEOS-5 (blue) profiles, the upper right plot shows the profile differences in temperature $(\mathrm{K})$, while the lower right plot shows the profile differences as a percent difference. 


\subsection{Water Vapor Measurements}

In addition to temperature (both Rayleigh/Vibrational-Raman and Rotational Raman), ozone and aerosol ASR, both the AT and STROZ mobile lidar system are capable of measuring water vapor by detecting the $408 \mathrm{~nm}$ water vapor Raman line. Earlier work in this area utilizing the AT lidar system was carried out during the NDACC MOHAVE I-II campaigns at Table Mountain Observatory ${ }^{11}$, and during the WAVES I-II and NWAVES-2009 campaigns at the Beltsville, MD Howard University research site ${ }^{12,13}$. Much of the MOHAVE work focused on whether or not $355 \mathrm{~nm}$ elastic returns caused fluorescence signals within the bandpass of the $407 \mathrm{~nm}$ water vapor channel that would thus bias the water vapor result high. Two types of Frost Point Hygrometer were flown in coincidence with the lidar observations - these sonde borne instruments are generally considered to be the "gold standard" for measuring atmospheric water vapor profiles. In the case of these current measurements at MLO such sonde flights were occasionally available during the various NOGJIE deployments, although the bulk of the comparisons were done versus the MET sondes launched from Hilo twice a day. All sondes were launched from Hilo and thus were not co-located with the lidar instruments. The sonde flights were used to provide a basis for calibration of the water vapor profiles measured by the two GSFC instruments as well as the NOAA lidar ${ }^{14}$. Water vapor profile comparisons have been carried out between the two GSFC trailers, the NOAA water vapor lidar, and the MET and FPH sondes launched from the airport at Hilo. Unfortunately there were only a handful of Frost Point Hygrometer (FPH) sonde launches during the NOGJIE deployment periods, and only a couple that were coincident in time with campaign observation times. While somewhat useful as a "sanity" check, the MET sonde water vapor profiles were not time-coincident with NOGJIE observations, and they were launched from the Hilo airport, and thus, depending on trade wind direction and strength did not sample the air above the MLO site very well.

The primary purpose of these campaign water vapor measurements was not only to assess the validity of the NOAA Lidar water vapor measurements, but it also presented an opportunity to check on the stability of the two GSFC water vapor system calibrations. All three of these lidars are NDACC affiliated. Table 1 above shows the number of nights where such inter-comparisons were possible. The STROZ Lidar was shipped from MLO to the NDACC site at Reunion Island in the Indian Ocean in January of 2014 and so did not participate during Parts E, F, or G.

\subsubsection{Water Vapor Calibration System}

Both the AT and STROZ-Lite mobile lidar systems use a Newport-Oriel Model 69931 Power Supply and matching NIST-traceable quartz calibration lamp system as a traveling calibration standard. The lamps mount on the top of the main telescope tube and illuminate the main mirror. The calibration lamp is warmed up and data taken for 10-15 minutes before an observing run, and randomly at the end of a data acquisition session, to monitor any changes in the data channels used to retrieve water vapor profiles (408 nm and $387 \mathrm{~nm}$ channels). An example is shown in Figure 14 for the AT water vapor calibration lamp during the Part-F deployment (Nov. 2015). The Figure clearly shows that, while the lamp calibration is stable to a few percent for most of the deployment, the calibration system clearly picks up the hardware/software changes made to the system after the first day of the deployment.

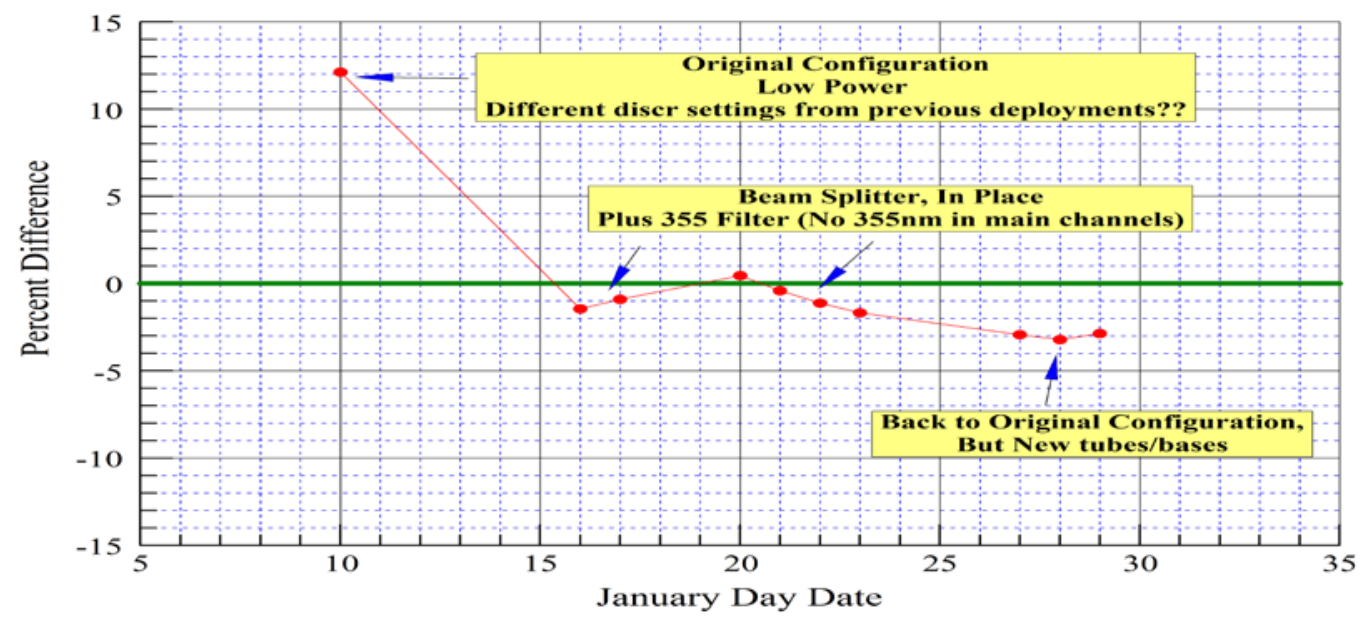

Figure 14. AT water vapor calibration ratio for the Part-F deployment. Hardware changes in the system lead to a $10-11 \%$ change in the calibration lamp ratio. 
As a further example, plot 15 and 16 show the calibration ratio for the Part B-D deployment (AT Lidar) and A-D deployments (STROZ Lidar). The plots show examples of both the changes between deployments, as well as larger than normal changes that can occur during a deployment (e.g. at the end of deployment $\mathrm{C}$ for the AT system). In general the

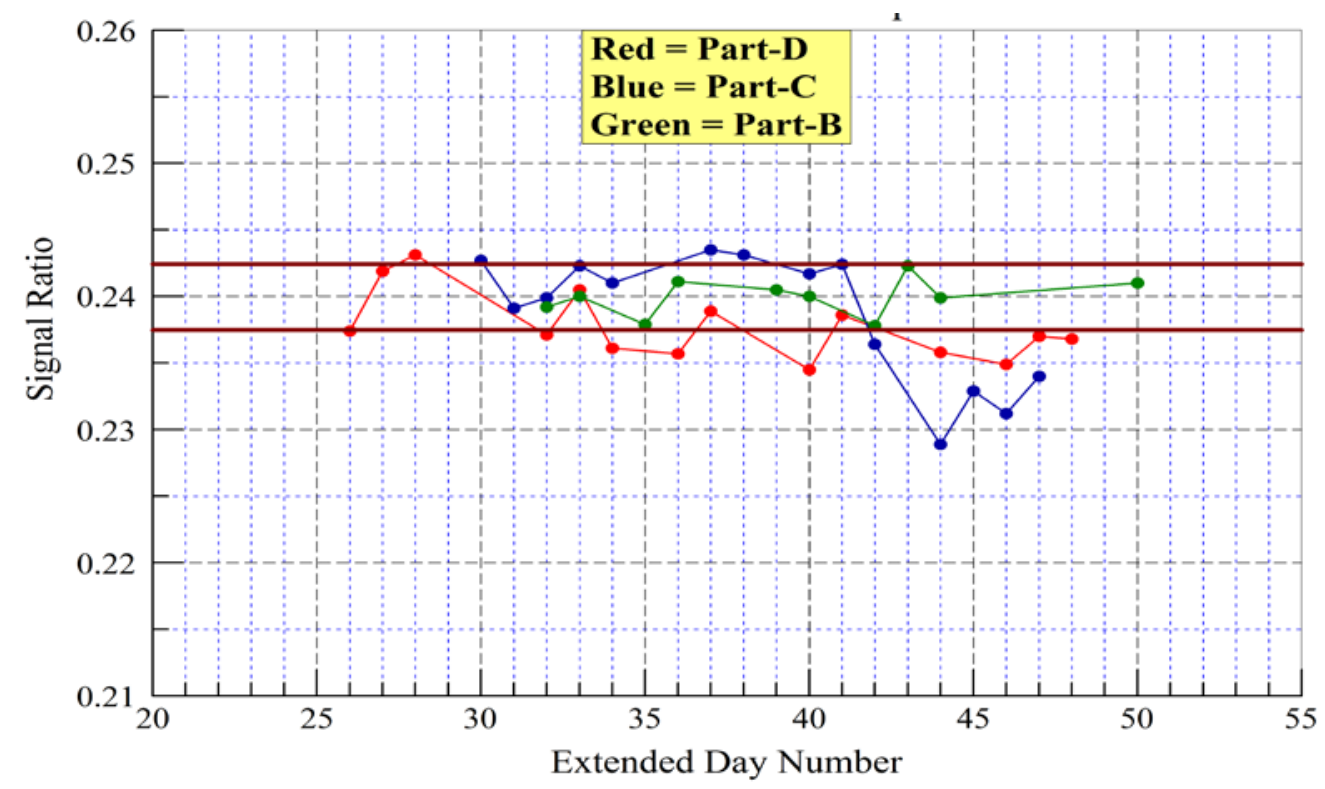

Figure 15. AT water vapor calibration ratio for the Part-B-D deployments. The X-axis is a simple means of plotting data from multiple deployments on one plot.

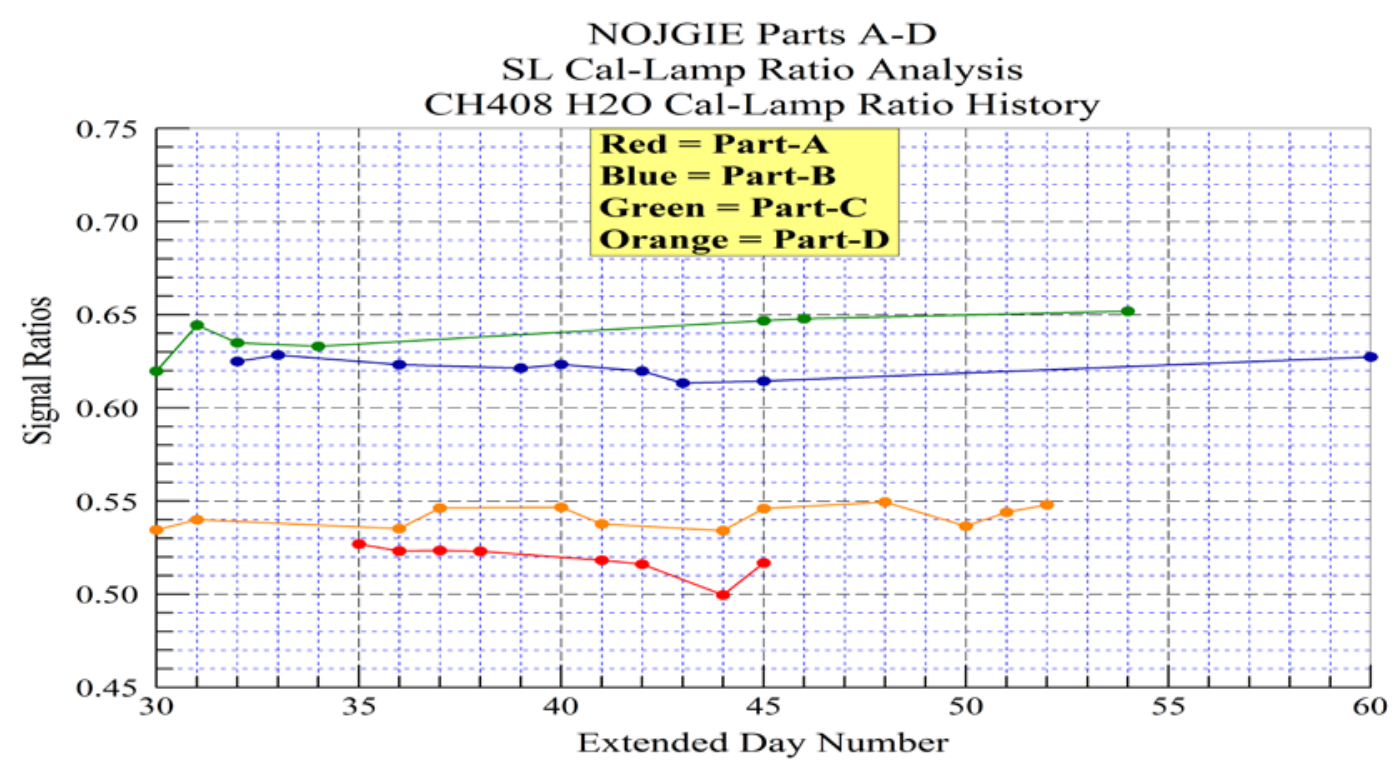

Figure 16. STROZ water vapor calibration ratios for the Part-A-D deployments. The X-axis is a simple means of plotting data from multiple deployments on one plot. 


\subsubsection{Selected Water Vapor Results}

An example of a typical water vapor profile comparison is shown in Figure 17. In this case we show a profile comparison between the AT, STROZ-Lite and NOAAA lidar systems and a coincident FPH sonde profile for a single night during the Part-B deployment, showing good agreement between the systems as well as between the lidar data and the sonde profile.

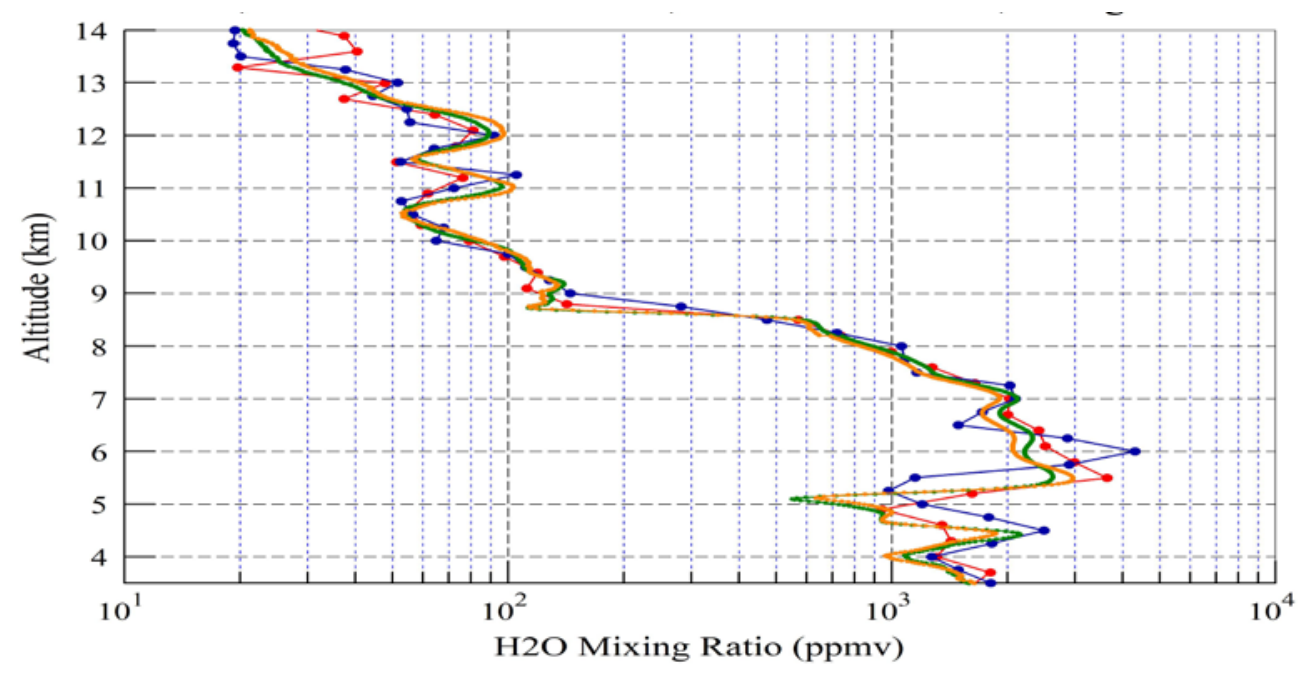

Figure 17. An example water vapor profile comparison for data taken on 8/2/2013. The NOAA lidar data is in red, the AT lidar in green, the STROZ-Lite lidar in orange, and the Hilo FPH sonde in blue.

Finally, Figures 18-20 show the summed profile comparisons within deployments B, C and D for the AT-STROZ, ATNOAA, and STROZ-NOAA comparisons. Shown in each plot are the summed profile comparisons, and two difference plots for these profile pairs in both raw and percent difference formats.
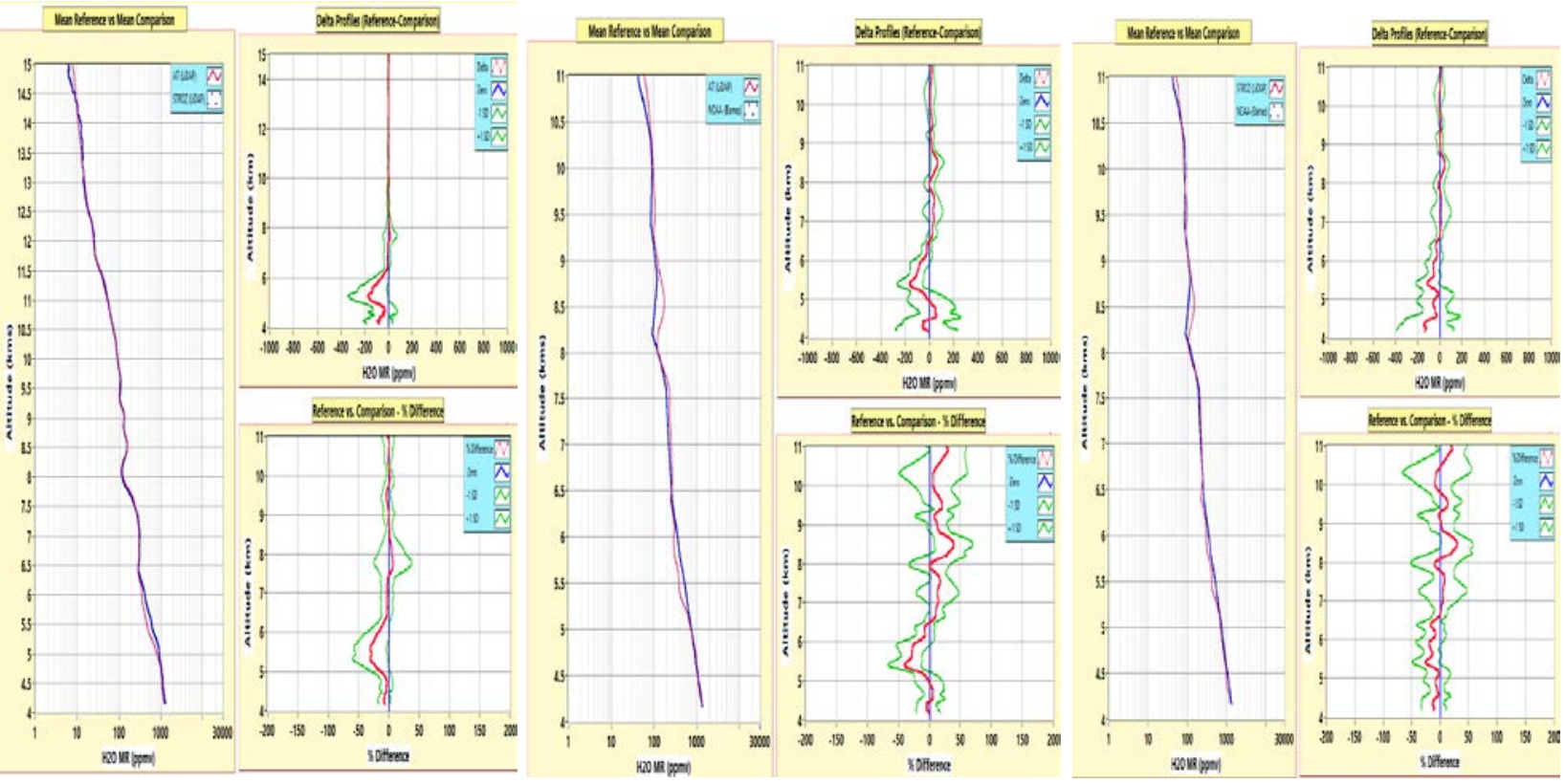

Figure 18. Part-B AT-STROZ, AT-NOAA, STROZ-NOAA averaged profile comparisons. The left plot shows the comparison between the mean AT (red) and GEOS-5 (blue) profiles, the upper right plot shows the profile differences in temperature (K), while the lower right plot shows the profile differences as a percent difference. 

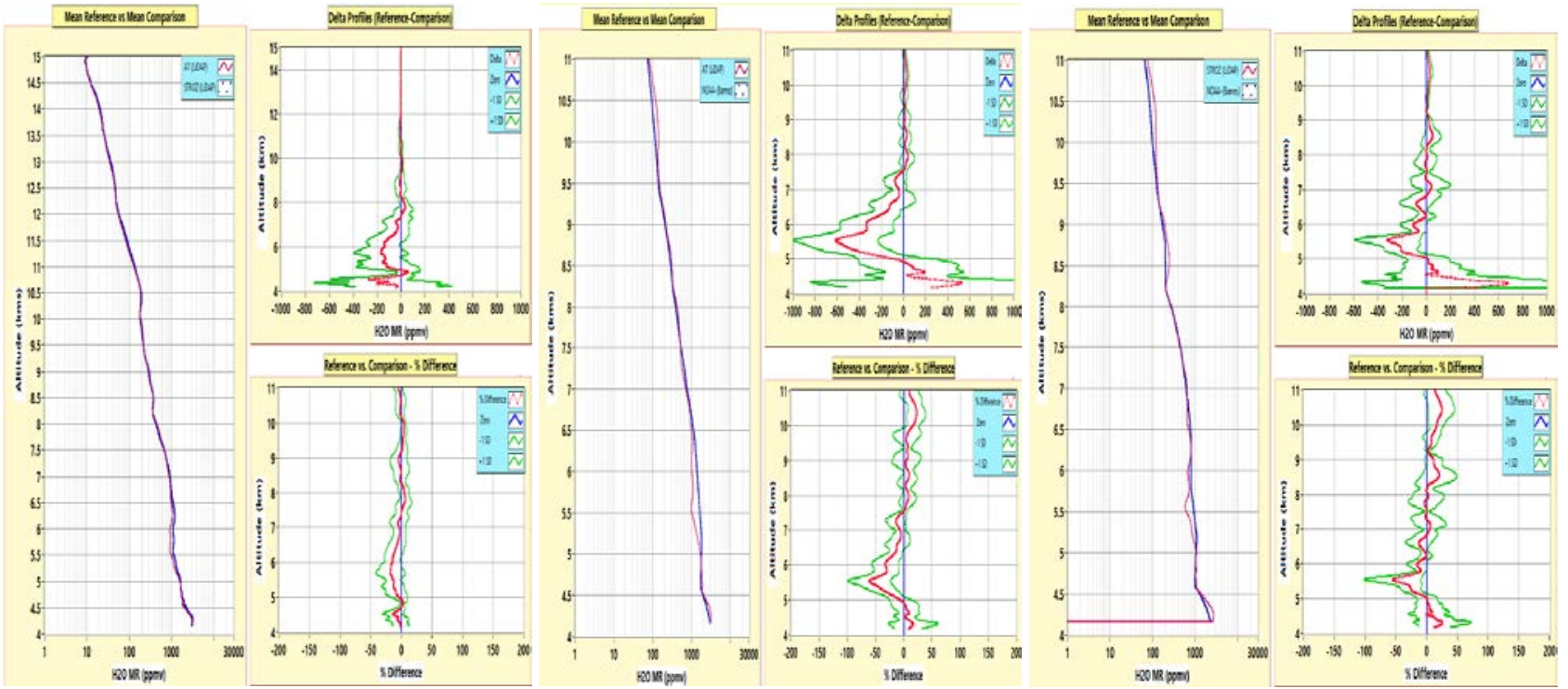

Figure 19. Part-C AT-STROZ, AT-NOAA, STROZ-NOAA averaged profile comparisons. The left plot shows the comparison between the mean AT (red) and GEOS-5 (blue) profiles, the upper right plot shows the profile differences in temperature (K), while the lower right plot shows the profile differences as a percent difference.
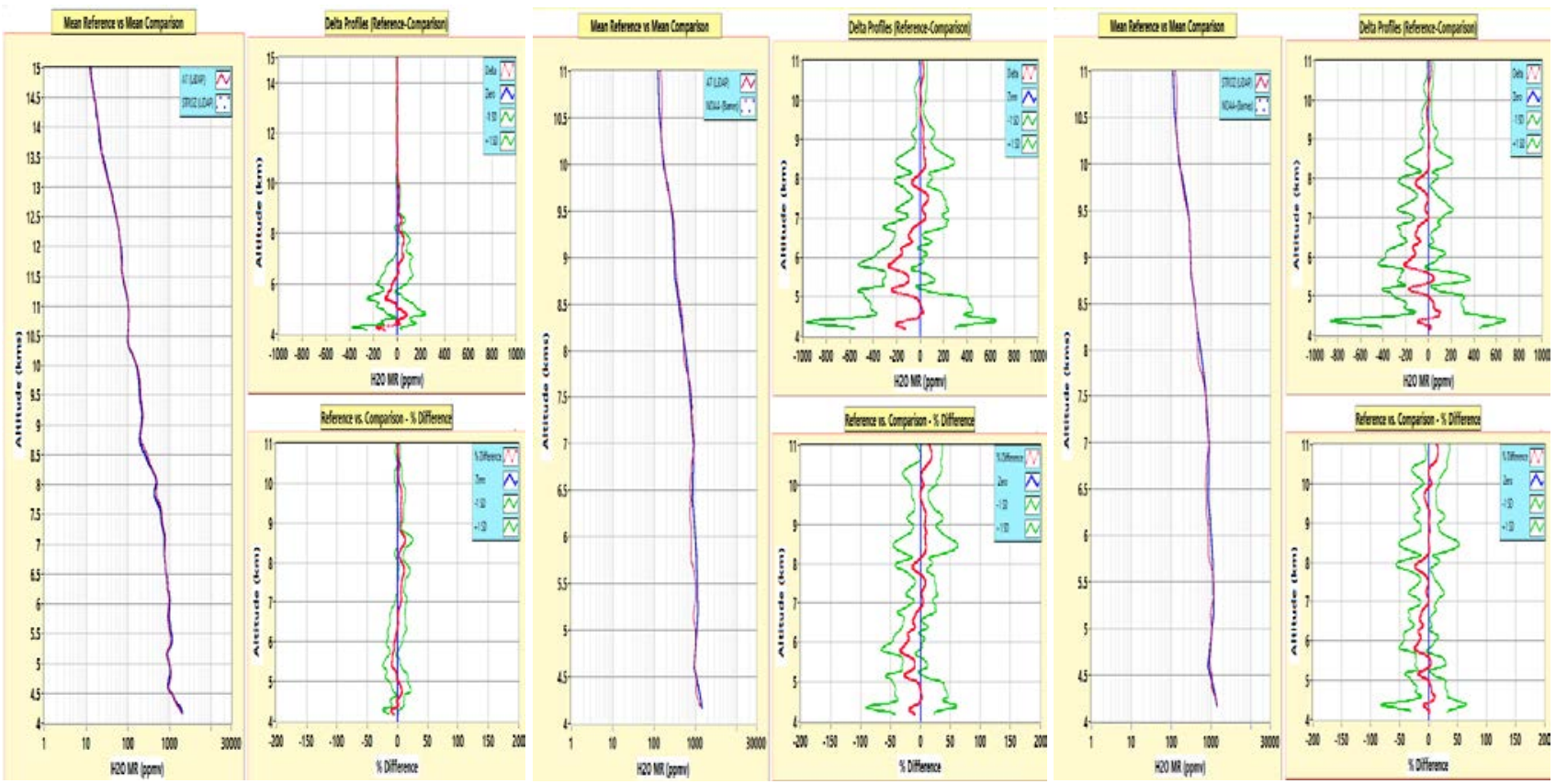

Figure 20. Part-D AT-STROZ, AT-NOAA, STROZ-NOAA averaged profile comparisons. The left plot shows the comparison between the mean AT (red) and GEOS-5 (blue) profiles, the upper right plot shows the profile differences in temperature (K), while the lower right plot shows the profile differences as a percent difference. 


\section{CONCLUSIONS}

In this paper we have summarized many of the intercomparisons results of the NDACC NOGJIE campaign. In particular we have focused on comparisons of ozone, Rayleigh-Raman temperature, Rotational Raman temperature, and water vapor profile retrievals acquired by lidar systems from NASA-JPL, NASA-GSFC, and NOAA at the Mauna Loa research site during 2012-2015. The results show excellent agreement between the various systems. In addition this campaign allowed one group (NASA GSFC) to test the stability of the water vapor systems in the AT and STROZ mobile lidar systems, along with a test of the stability of the calibration of the Rotational Raman temperature system that is part of the AT system. In both cases, we find that the systems in place do well at tracking the changes in the water vapor and rotational Raman temperature both within a deployment and over the entire campaign time period. From the standpoint of an NDACC validation campaign, both the JPL lidar and the NOAA lidar performed as expected. For the JPL lidar the ozone results showed better than 5\% agreement with the STROZ lidar between 17 and $45 \mathrm{~km}$ which has been a very typical result in past similar campaigns. The temperature results are within the expected limits. The water vapor comparisons are still under analysis which will continue.

\section{ACKNOWLEDGEMENTS}

The authors would like to thank the NASA Upper Atmosphere Research Program for the funds to operate and deploy the NDACC lidars. We would also like to thank the NOAA Earth System Research Laboratory for the courtesy shown in hosting the two lidar trailers at the Mauna Loa Observatory during these studies.

\section{REFERENCES}

[1] McGee, T. J., Whiteman, D., Ferrare, R., Butler, J. J., and Burris, J. F.,”STROZ LITE: NASA Goddard Stratospheric Ozone Lidar Trailer Experiment," Optical Engineering, 30, 31-39, 1991

[2] McGee, T. J., Gross, M., Ferrare, R. Heaps, W. S. and Singh, U. "Raman DIAL Measurements of Stratospheric Ozone in the Presence of Volcanic Aerosols," Geophys. Res. Lett. , 20, 955-958, 1993

[3] McGee, T.J. Gross, M., Singh, U.N., Butler, J. J. , and Kimvilakani, P., "An Improved Stratospheric Ozone Lidar", Opt. Engin., 34, 1421-1430, 1995

[4] Behrendt A. and Reichardt, J., "Atmospheric temperature profiling in the presence of clouds with a pure rotational Raman lidar by use of an interference-filter-based polychromator”, Appl. Optics, 39, 1372-1378, (2000)..

[5] McDermid, I.S., Godin, S. M., Walsh, T., D., "Lidar measurements of stratospheric ozone and intercomparisons and validation”, Appl. Opt, 29, 4914-4923, (1990), https://doi.org/10.1364/AO.29.004914

[6] Ferrare, R. A., McGee, T. J., Whiteman, D., Burris, J., Owens, M., and Butler, J., "Lidar Measurements of Stratospheric Temperature During STOIC”, J. Geophys. Res., 100, 9303-9312, 1995

[7] Kim, D., Cha, H., Lee, J., and Bobronikov, S.,"Pure rotational Ra-man lidar for atmospheric temperature measurements”, J. Korean Phys. Soc., 39, 838-841, (2001)

[8] Alpers, M., Eixmann, R., Fricke-Begemann, C., Gerding, M., and Höffner, J., “Temperature lidar measurements from 1 to $105 \mathrm{~km}$ altitude using resonance, Rayleigh, and Rotational Raman scattering, Atmos. Chem. Phys., 4, 793-800, doi:10.5194/acp-4-793, (2004, 2004).

[9] Nedeljkovic, D., Hauchecorne, A., and Chanin, M.-L., "Rotational Raman lidar to measure the atmospheric temperature from ground to $30 \mathrm{~km}$ ”, IEEE T. Geosci. Remote, 31, 90-101, 1993

[10]Zuev, V. V., Gerasimov, V. V., Pravdin, V. L., Pavlinsky, A. V., Nakhtigalova, D. P., "Tropospheric temperature measurements with the pure rotational Raman lidar technique using nonlinear calibration functions," Atmos. Meas. Tech., 10, 315-332, (2017).

[11]Leblanc, T., Walsh, T. D., McDermid, I. S., Toon, G. C., Blavier, J.-F., Haines, B., Read, W. G., Herman, B., Fetzer, E., Sander, S., Pongetti, T., Whiteman, D. N., McGee, T. J., Twigg, L., Sumnicht, G., Venable, D., Calhoun, M., Dirisu, A., Hurst, D., Jordan, A., Hall, E., Miloshevich, L., Vömel, H., Straub, C., Kampfer, N., Nedoluha, G. E., Gomez, R. M., Holub, K., Gutman, S., Braun, J., Vanhove, T., Stiller, G., and Hauchecorne, A., "Measurements of humidity in the atmosphere and validation experiments (MOHAVE)-2009: overview of campaign operations and results”, Atmos. Meas. Tech., 4, 2579-2605, doi:10.5194/amt-4-2579-2011, 2011

[12] Whiteman, D. N., Adam, M., Barnet, C., Bojkov, B., Delgado, R., Demoz, B., Fitzgibbons, J., Forno, R., Herman, R., Hoff, R., Joseph, E., Landulfo, E., McCann, K., McGee, T., Miloshevich, L., Restrepo, I., Schmidlin, F. J., 
Taubman, B., Thompson, A., Twigg, L., Venable, D., Vomel, H., Waltham, C., "The Water Vapor variability Satellite/Sonde (WAVES) Field Campaigns”, https://ntrs.nasa.gov/search.jsp?R=20080030242 2018-0910T01:52:48+00:00Z

[13] Adam, M., Demoz, B. B., Whiteman, D. N., Venable, D. D., Joseph, E., Gambacorta, A., Wei, J., Shepard, M. W., Miloshevich, L. M., Barnet, C. D., Herman, R. L., Fitzgibbon, J., and Connell, R., “ Water Vapor Measurements by Howard University Raman Lidar during the WAVES 2006 Campaign”, Jour. Of Atm. And Oceanic Tech., 27, 4260, (2010)

[14]Barnes, J. E., Kaplan, T., Vomel, H., and Read, W. G, "NASA/AURA/Microwave Limb Sounder Water Vapor Validation at Mauna Loa Observatory by Raman Lidar”, J. Geophys. Res., 113, D15S03, doi:10.1029/2007JD008842, (2008). 